\title{
EFFECTS OF ORAL PROPHYLAXIS METHODS ON THE SURFACE ROUGHNESS OF TOOTH COLOURED RESTORATIVE MATERIALS
}

\author{
Ashraf Ibrahim*, Weam Douidar* ${ }^{* *}$ and Sayed Ghorab ${ }^{* * *}$
}

\begin{abstract}
Introduction: many new aesthetic restorative materials are used in clinical practice to obtain better polishability and wear resistance but their properties and the surface changes that occur after oral prophylaxis are still unknown.

Aim of the study: The present study aimed to evaluate the effects of two oral prophylaxes on the surface roughness of three different brands of aesthetic restorative materials.

Materials and methods: A total of 90 standardized specimens, were fabricated using a cylindrical plastic mold, $10 \mathrm{~mm}$ diameter $\times 2 \mathrm{~mm}$ depth, of three different restorative materials; resin modifiesd glassionomer (RMGIC) (Fuji Filling LC), bioactive ionic resin(Activa Bioactive) and nanofilled resin composite (Filtek ${ }^{\mathrm{TM}} \mathrm{Z} 350 \mathrm{XT}$ ) 30 specimens of each restorative material, All Specimens were polished with a series of aluminum oxide polishing discs (Sof-Lex). specimens of each restorative materials were randomly divided into three subgroups of 10 specimens according to the treatment it will receive. Group I received no treatment. Group II was polished with rubber cup and proKlene Prophylaxis Paste . Group III was polished with AIRFLOW® Prophylaxis. Surface roughness measurements were performed using ESEM (QUANTA 200, FEI CO., OR, USA), then, data were analyzed by two-way analysis of variance (ANOVA), and mean values were compared by Tukey's honestly significant difference test $(\alpha=0.05)$.
\end{abstract}

Results: It was found that surface roughness values were changed significantly between the control, 1st and 2nd evaluations $(\mathrm{p}<0.05)$ for each material and between the two prophylactic methods and control $(\mathrm{p}<0.05)$, showing that the change in surface roughness depended on the type of restorative material and prophylactic treatment. Roughness was significantly higher after the pumice and rubber cup $(\mathrm{p}<0.05)$.

Conclusion: Prophylaxis using pumice and rubber cup showed significantly the highest surface roughness of restorative material. The nanofilled composite was the least to be affected.

KEYWORDS: Surface ruoughness, Oral prophylaxis, Resin modified glassionomer, Nanofilled resin composite, Bioactive ionic resin.

\footnotetext{
* Lecturer, Department of Operative, Faculty of Dentistry, Mansoura University, Mansoura, Egypt.

** Lecturer, Department of Operative Dentistry, Faculty of Dentistry, Mansoura University, Mansoura, Egypt.

*** Lecturer, Department of Dental Biomaterias, Faculty of Dentistry, Mansoura University, Mansoura, Egypt.
} 


\section{INTRODUCTION}

The increasing and continuous demand for toothcolored restorations and the asking for amalgam replacements have led to an increased demand for direct tooth-colored restorative materials in the past few years. Two major types of tooth colored restoratives in dental market are glass ionomers and composites, where each partially or completely fulfill most of the requirements of a successful restorative material. ${ }^{1,2}$ A hybrid of glass-ionomer and composite has emerged to take advantage of the positive attributes of both. Examples of these hybrid materials include resin-modified glassionomer cements, compomers (polyacid-modified resin composites) and giomers (pre-reacted glass ionomer). ${ }^{3,4}$ Despite their advantages, RMGI, compomer and giomer show reduced fluoride release compared to conventional glass ionomer. Also lower mechanical properties compared to composites. ${ }^{5,6,7}$

A new bioactive ionic resin (Activa bioactive restorative) provided by Pulpdent to dental profession claimed to be strong, esthetic, bioactive restoratives that release and recharge calcium, phosphate and more fluoride than glassionomers. Activa mimics the physical and chemical properties of natural teeth by combining the strength and esthetics of composites with all the benefits of glass ionomers, chemically bonds and better seal with teeth against bacterial leakage, and the continuous diffusion of calcium, phosphate and fluoride ions provides long-term benefits for patients. ${ }^{8}$

Restorative and periodontal treatment need an important integral part which is hygiene maintenance therapy. A routine part of the maintenance appointment is the removal of stains and plaque from all accessible tooth surfaces. a rubber cup and pumice are widely known method among professionals to remove dental stains and plaque. ${ }^{9}$ However, this method has limitations because its ability to remove stains in grooves and malaligned teeth is limited. To overcome these limitations, air polishing powders(APD) have been introduced for stain removal. ${ }^{9}$ The stain removal efficacies of a rubber cup with pumice and air polishing are similar, but the a rubber cup and pumice need more time than for air polishing. In addition, the efficacy of air polishing in stain removal is more accurate. ${ }^{10}$

The influence of different prophylaxis procedures on surface roughness of different types of glassionomers and composite resins has been investigated in previous studies and it has been reported that the effect of prophylaxis treatments is material dependent. ${ }^{9,10}$ New bioactive ionic resin aesthetic restorative materials recently appeared in the dental market known as Activa bioactive restorative has been introduced. There is little information available in dental literature about the influence of prophylaxis procedures on this material. The aim of the present study was to evaluate the effect of two prophylaxis methods, including pumice with rubber cup, and air polishing powders (APD) on a new bioactive ionic resin surface roughness. The research null hypothesis was that the surface roughness of the dental restoration wouldn't be influenced by the type of material and oral prophylaxis method.

\section{MATERIAL AND METHODS}

In the this study, three dental restorative materials were investigated (table 1). A total of 90 standardized specimens, were fabricated using a cylindrical plastic mold, $10 \mathrm{~mm}$ diameter $\times 2 \mathrm{~mm}$ depth, of three different restorative material; resin modifiesd glassionomer (RMGIC) (Fuji Filling LC), bioactive ionic resin(Activa Bioactive) and nanofilled resin composite (Filtek ${ }^{\mathrm{TM}}$ Z350 XT) 30 specimens of each restorative material, the specimens were prepared by standardized method by applying the mold above a glass slap covered with Mylar strip (SS White, USA ) then injection of the restorative material into the mold, covering it again with Mylar strip, placing a glass slide on top 
then the material was pressed between both glass slides to extrude excess material and to reduce voids at the surface.

All the materials were prepared, mixed and dispensed according to manufacturer instructions. Each restorative material was placed in bulk pack technique in the mold using Optra Sculp modeling instrument for Activa, the syringe was loaded in its specific applier. curing was performed according to manufacturer's instructions with a LED light curing unit (LITE Q, Model: LD-107, Monitex, Taiwan) through the glass slide and Mylar strip on the top of the specimens once being pressed. The curing light was placed perpendicular to each specimen's surface and with direct contact with the glass slide. The light intensity was measured at $800 \mathrm{~mW} / \mathrm{cm} 2$ and verified with a digital readout dental radiometer (Blue phase Meter, Ivoclar vivadent).

Additional 20 seconds curing on both sides of the specimens was done after removing the stripes and glasses. The resulting specimen's extra flanges were removed with Sic paper (1200 grit) at a 90 degree angle. Finally the specimens were removed from the mold. The specimens were immediately finished and polished to simulate the clinical condition. The same operator prepared, finished and polished all specimens to reduce variability. The specimens were examined for voids and labeled on its unobserved surface.

The specimens were finished and polished with three step Sof-Lex aluminum oxide disc system. The specimens were then polished with Sof-Lex discs at descending sequence of abrasiveness; dark blue Sof-Lex disc (Medium), fine Sof-Lex (blue) and superfine Sof-Lex (light blue) with uniform light pressure and a planar motion from the bulk of the restoration toward the margins. The specimens were stored for 24 hours in dark container filled with distilled water at $37^{\circ} \mathrm{C}$ prior to subjecting them to prophylactic method. Specimens of each of the three restorative materials were randomly divided into three groups of 10 specimens each according to the surface treatment that it will recive.

Group I: in which the specimens did not subjected to any prophylaxis.

Group II: received rubber cup and proklene prophylaxis paste polishing mounted in contraangle handpiece running in slow-speed at $2000 \mathrm{rpm}$ over each tested specimen for 10 seconds without interruption.

Group III: Received air-polishing using a standard air polishing unit for 10 seconds (EMS Air Flow Handy, EMS SA, Geneva, Switzerland), installed adhering to the manufacturer's instructions.

The working pressure was kept at 2 Bar. The angulation of instrument nozzle was kept perpendicular to slide surface. Spraying distance was kept constant which was $10 \mathrm{~mm}$. Spraying time was the same which could be ensured by an electronically controlled aperture opening that placed between the slide surface and the tip of the instrument.

The powder chamber of the air polishing unit was filled to the top with AIRFLOW ${ }^{\circledR}$ Plus powder. After each air-polishing period, the powder chamber of the instrument was regularly observed and refilled to ensure maximum reproducibility of powder emission. At the end, the tested specimens were washed by water for 10 seconds using a triple syringe, and then dried with the aid of jets of air for 5 seconds and evaluated for surface roughness by using ESEM (QUANTA 200, FEI CO., OR, USA) combined with image analysis to provide both qualitative and quantitative assessments of surface roughness.

Specimens were micro photo graphed at X1000 magnification and the images were analyzed quantitatively using microscopy installed image analysis software (XT document) . 
TABLE (1)

\begin{tabular}{|c|c|c|c|c|}
\hline Material & Specification & Manfacture & Composition & Batch number \\
\hline $\begin{array}{l}\text { Fuji Filling } \\
\text { LC }\end{array}$ & $\begin{array}{l}\text { Resin modified } \\
\text { glassionomer }\end{array}$ & $\begin{array}{c}\text { GC Co, } \\
\text { Tokyo, Japan }\end{array}$ & $\begin{array}{l}\text { Paste A: Alumino-fluoro-silicate glass amorphous) (75- } \\
85 \%) 2 \text { - Hydroxyethylmethacrylate (10-12\%) } \\
\text { Urethandimethacrylate (2-5\%) Paste B: Distilled water } \\
\text { (20-30\%) Polyacrylic acid (20-30\%) } \\
\text { Urethandimethacrylate }(12-15 \%) \text { Silicon dioxide (fumed/ } \\
\text { amorphous) (10-15\%) }\end{array}$ & 1604218 \\
\hline $\begin{array}{l}\text { Activa } \\
\text { Bioactive- } \\
\text { Restorative }\end{array}$ & $\begin{array}{l}\text { Bioactive ionic } \\
\text { resin }\end{array}$ & $\begin{array}{c}\text { Pulpodent } \\
\text { Corporation, } \\
\text { Watertown, } \\
\text { MA }\end{array}$ & $\begin{array}{l}\text { Part A: Diurethane dimethacrylate and other methacrylate- } \\
\text { based monomers and oligomers; polyacrylic acid/maleic } \\
\text { acid copolymer, water, barium } \\
\text { Borosilicate glass, silica, reducing agents, photo initiator, } \\
\text { colorants. } \\
\text { Part B: Diurethanedimethacrylate and other methacrylate- } \\
\text { based Monomers and oligomers; } \\
\text { aluminoflurosilicate ionomer glass, silica, oxidizing agents. } \\
\text { (The blend of diurithane and other methacrylate with } \\
\text { modified poly acrylic acid is } 44.6 \% \text {, Amorphous silica is } \\
6.7 \% \text { ) }\end{array}$ & 160314 \\
\hline $\begin{array}{l}\text { Filtek }^{\mathrm{TM}} \\
\text { Z350 XT }\end{array}$ & $\begin{array}{l}\text { Nano filled } \\
\text { resin composite }\end{array}$ & $\begin{array}{l}\text { 3M ESPE } \\
\text { St Paul, MN, } \\
\text { USA }\end{array}$ & $\begin{array}{l}\text { Matrix: UDMA, Bis-GMA, Bis-EMA,TEGDMA } \\
\text { Filler: silica nanofiller }(5-75 \mu \mathrm{m}) \text {, zirconia/silica } \\
\text { nanocluster }(0.6-1.4 \mu \mathrm{m})\end{array}$ & N213204 \\
\hline
\end{tabular}

\section{RESULTS}

The mean value of surface roughness of the control and two prophylaxis methods for each tested materials are shown in table (2). There was significant difference in surface roughness between the tested materials in control groups (Nanofilled resin composite, Resin modified glassionomer, Activabioactive) $\mathrm{p}<0.05$, whereas resin modified glass ionomer control yielded statistically higher surface roughness than the nanofilled and
Activabioactive $(p<0.05)$. The nanofilled control group showed the smoothest surface. For each tested material, two prophylaxis methods resulted in significant surface roughening when compared to the control group $(\mathrm{p}<0.05)$. The air powder polish for each material showed less roughness. The surfaces of the resin modified glass ionomer were the roughest, and those of the nanofilled were the smoothest after both types of prophylaxis. (fiqures 1,2 )

TABLE (2) Mean and standerd deviation values of surface roughness of different restorative materials polished with different oral hygiene prophylaxis systems. (The results of Tukey test).

\begin{tabular}{|l|l|l|l|l|}
\hline Material & Nanofilled resin composite & Resin modified glass-ionomer & Activabioactive & P value \\
\hline & Mean \pm SD & Mean \pm SD & Mean \pm SD & \\
\hline Control & $151.62 \pm 3.72^{\mathrm{g}}$ & $183.75 \pm 12.13^{\mathrm{e}}$ & $170.85 \pm 6.30^{\mathrm{f}}$ & 0.000 \\
\hline pumice and rubber cup & $230.17 \pm 4.005^{\mathrm{d}}$ & $267.76 \pm 8.72 \mathrm{a}$ & $249.29 \pm 5.43 \mathrm{~b}$ & 0.000 \\
\hline air-powder polishing device & $204.90 \pm 2.18^{\mathrm{c}}$ & $212.95 \pm 3.007^{\mathrm{d}}$ & $212.65 \pm 5.11^{\mathrm{d}}$ & 0.000 \\
\hline P value & 0.000 & 0.000 & 0.000 & 0.000 \\
\hline
\end{tabular}




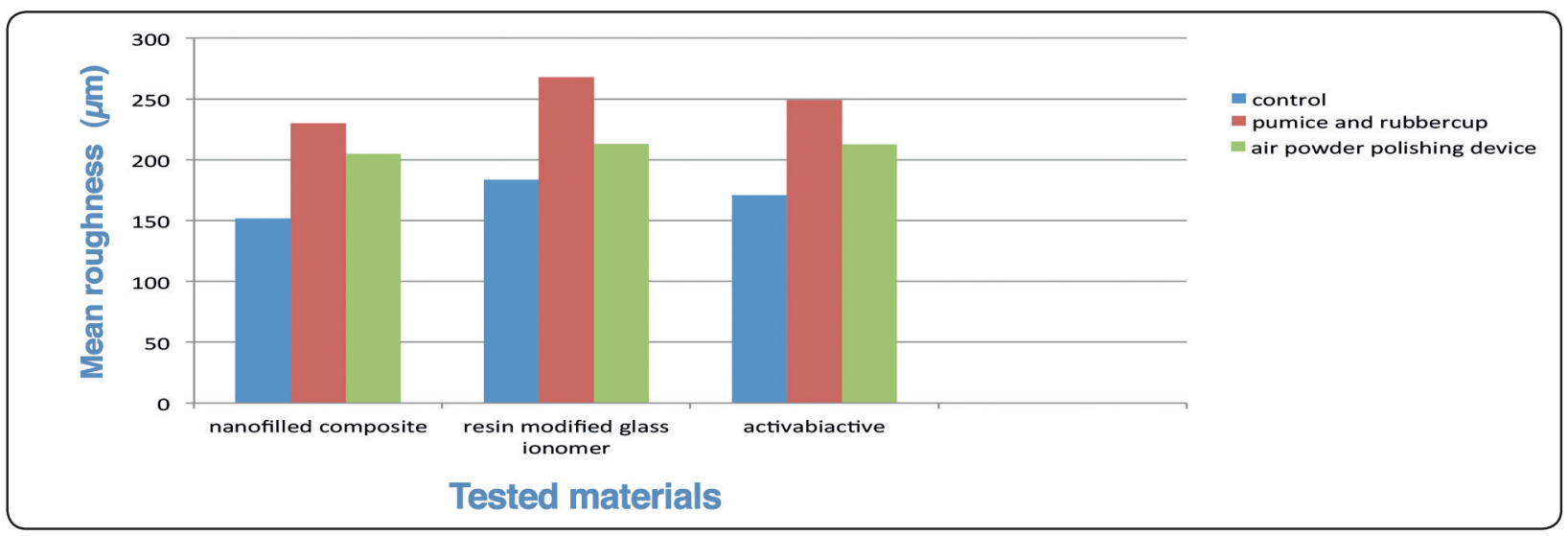

Fig. (1): Mean surface roughness of tested materials.

\section{Surface roughness of tested materials:}
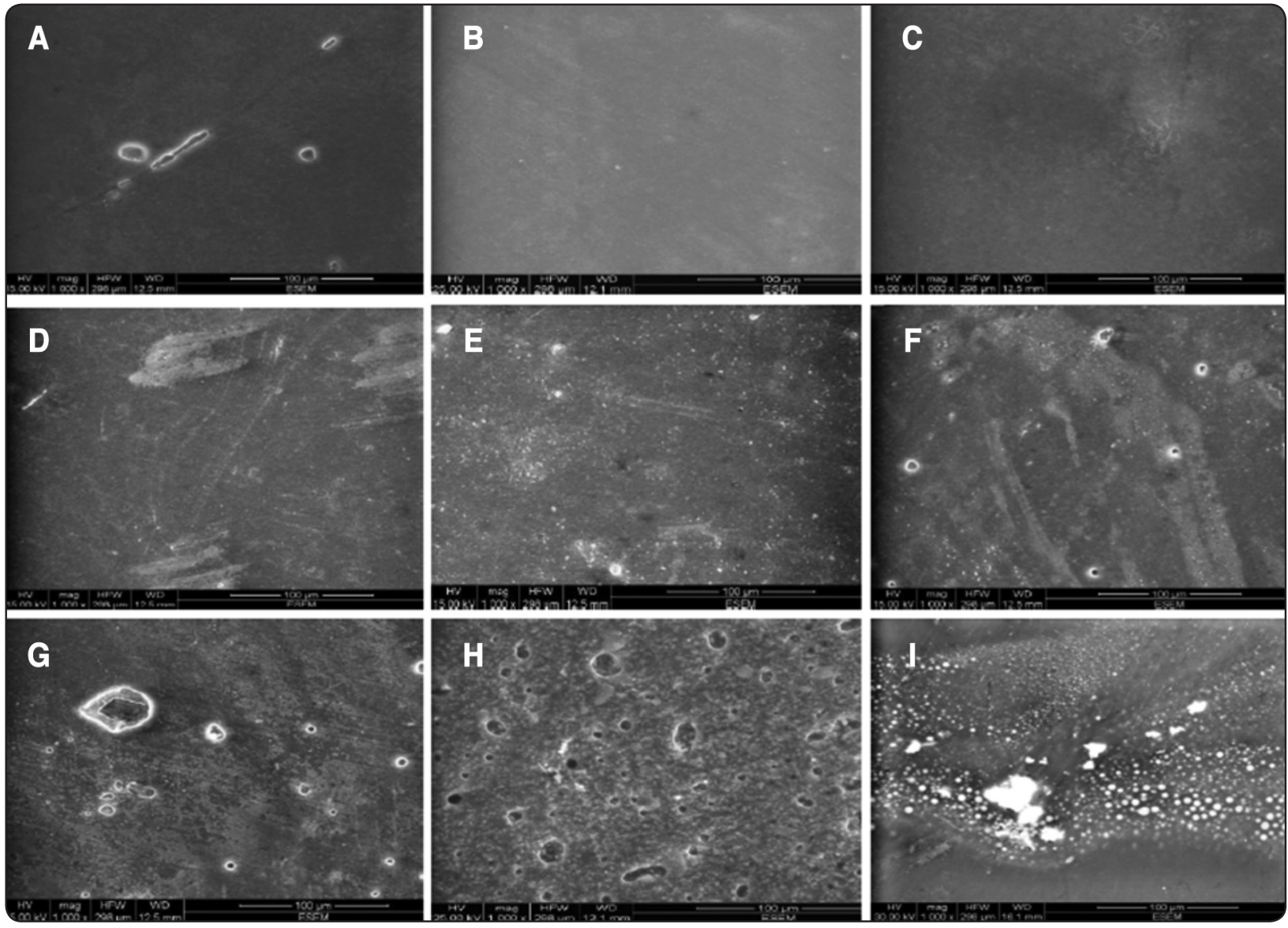

Fig. (2) ESEM photographs of study groups tested at 1000× magnification. A-Nano filled resin composite control, Nano filled resin composite pumice and rubber cup, C-Nano filled resin composite air-powder polishing, D-Resin modified GIC control, E-Resin modified GIC pumice and rubber cup, F-Resin modified GIC air-powder polishing G-Activa bioactive restorative control, H-Activa bioactive restorative pumice and rubber cup, I-Activa bioactive restorative air-powder polishing 


\section{DISCUSSION}

It is well known that the survival of bacteria in the oral cavity is essentially depending on their adhesion to hard surfaces, such as those of teeth, prothesis and restorative materials. ${ }^{11}$ Therefore, the initial adhesion and the retention of oral bacteria greatly dependent on the surface roughness of intraoral hard surfaces. ${ }^{11,12}$ The discoloration potential of esthetic restorations as well as secondary caries and gingival inflammation is a sequel of restorations roughness. 12,13,14,15 Consequently, this in-vitro study has been conducted to investigate the effect of two different types of oral hygiene maintenance prophylaxis methods on the surface rouhgness of three major types of restorative materials. Restorative materials selection for this study was based on several parameters. First, all of the materials have been widely used for restoring cervical lesion. Second, there was no study comparing all these restorative materials together regarding roughness due to oral prophylaxis method. Third, they had different composition leading to obtain possibly different results.

The smoothest composite resin surface is obtained when the material is cured against mylar polyester matrix strip. ${ }^{16,17,18}$ Careful placement of the matrix, recontouring the restorations and removing excess material are often clinically necessary. ${ }^{19}$ Several studies reported flexible aluminum oxide disks were the best instruments for producing smooth surface restorations compared to abrasive impregnated disks. ${ }^{20-22}$ So, aluminum oxide discs are most often recommended because their malleability promotes a homogeneous abrasion of the resin matrix and fillers. For these forementioned reasons, all specimens were polished with a series of SofLex aluminum oxide polishing discs in the present study. Planar motion was used with all specimens, as a previous study demonstrated that this motion produced significantly lower mean surface roughness values. ${ }^{23}$
In this study, a single person carried out all hygiene maintenance procedures to minimize the effects of operator variability, and the average roughness (Ra) was used to express the surface roughness. ${ }^{24,25}$ Surface roughness can be measured by various qualitative (optical and scanning electron microscopy) and quantitative (surface profile analysis). Furthermore, both of Atomic Force Microscopy (AFM) and ESEM could be used for qualitative \& quantitative assessment of surface roughness. ${ }^{26}$

In the present study surface roughness was measured by an ESEM, which has the ability to capture an image for the tested specimens with magnification up to X 100,000. The main advantage of ESEM is that the specimens could be observed inside its low-vacuum chamber in a relatively wet condition. 25 Moreover; it can examine the noncontaminated, hydrated and even living samples without'long'tedious dehydration procedures, which may affect the integrity of the biological specimens. In comparison with SEM, ESEM provides a reliable idea about the material behavior in relatively humid environment. ${ }^{27}$

During oral hygiene maintenance therapy, cervical restorations are unavoidably subjected to prophylactic procedures because of stains and heavy plaque depositions are commonly found near gingival tissues. A variety of prophylactic agents used in hygiene maintenance procedures are with varying extents of abrasiveness and brushes or rotary rubber cups as carriers. Clinical practice received air-powered devices for the purpose of hygiene treatment. With these devices air jet combined with a small stream of water, containing sodium bicarbonate particles are propelled, creating a slurry that is directed onto the tooth surface. ${ }^{28}$ Extrinsic stains were removed faster by air polishers than hand scalars, strips, and abrasives in rubber cups without causing significant changes in the surface topography of the enamel or dentin. ${ }^{29}$ 
The results of this study indicated that significant increase in surface roughness of all the prophylaxis treatments in comparison with the control group, and pumice with rubber cup group showed a dramatic increase in surface roughness followed by air powder. On the basis of these data, the null hypothesis stated of this study is totally rejected. The result is in accordance with Yap et al. ${ }^{30}$ and previous studies that have shown that the use of prophylactic polishing pastes, tooth brushing and sonic and ultrasonic periodontal instruments significantly increases the surface roughness of restorative materials..$^{31-33}$

The result of this study is in accordance with Johnson et al 34 who stated that regardless of the polishing agent used in air polisher, whether sodium bicarbonate or aluminum trihydroxide, the use of these agents should be avoided on dental restorative materials. The effect of an air polishing system that utilized sodium bicarbonate powder were evaluated on the surface characteristics of various restorative materials and, they found that the greatest change in roughness recorded for composite resins..$^{35,36}$ However, produced higher surface roughness with prophylactic paste,rubber cup than the corresponding air polish powder. This could be related to the abrasiveness of paste and different powder composition used in air powder polish (erythritol based powder). The results of the study was not in accordance with previous studies ${ }^{30,37}$ that found greater roughness with the prophylactic treatment carried out with bicarbonate jet instead of rubber cup and prophylactic paste.

Surface roughness as a result of hygiene procedures are material-dependent. Composites are composed of two phases, fillers embedded in a resin/ polymer matrix. ${ }^{38}$ Matrix phase is preferentially removed during hygiene procedures, ${ }^{39-41}$ as the abrasives employed in prophylactic agents are harder than the resin matrix. These abrasives can even be similar in hardness to the fillers of some composite materials. ${ }^{28}$ Therefore, filler particles are exposed, as the resin matrix is selectively removed, resulting in a rough surface. ${ }^{28}$

Both oral prophylaxis methods dramatically roughened resin modified glass ionomer specimens compared with the other tested materials which could be attributed to its heterogeneous and biphasic nature. ${ }^{41,42}$ The weak polysalt matrix phases were easily removed during maintainance procedures, while the harder unreacted fluoroaluminosilicate (FAS) glass particles (average of $1 \mathrm{~mm}$ ) protruded from the surface.

While, nanofilled composite showed the least surface roughness values achieved after oral prophylaxis methods, which could be attributed to its chemical composition which is illustrated in material and methods section. It lacks the resin modified glass ionomer heterogeneous, biphasic chemical composition of with the absence of FAS glass fillers (average of $1 \mathrm{~mm}$ particle size) which seems to predominant the behavior of resin modified glass ionomer rather than the resin part with its nano-filler technology. Although the particles size of both Fuji 2 LC and Activa nearly the same, the surfaces of activa were smoother in control and two prophylactic methods. This can attributed to other parameters such as differences in distribution, shape, and number of particles, type of resinous matrix, interfacial bonding between particles and matrix; and interfacial bonding between particles that may contribute to a material's surface finish.

From this study, prophylactic oral hygiene maintaince methods should be used with caution when there is dental restoration cervically. Further studies are recommended to explore the best technique for removal of plaque effectively without determintal effect on surface roughness of restoration. 


\section{REFERENCES}

1. Yadav RD, Raisingani D, Jindal D, Mathur R. A Comparative Analysis of Different Finishing and Polishing Devices on Nanofilled, Microfilled, and Hybrid Composite: A Scanning Electron Microscopy and Profilometric Study. Int J Clin Pediatr Dent 2016; 9:201-208.

2. Adeleke A, Oginni A. Clinical evaluation of resin composite and resin modified glass ionomer cement in non-carious leasions. J West Afr Coll Surg 2012; 2: 21-37.

3. Berzins DW, Abey S, Costache MC, Wilkie CA, Roberts HW. Resin- modified glass-ionomer setting reaction competition. J Dent Res 2010; 89: 82-86.

4. Chitnis D, Dunn WJ, Gonzales DA. Comparison of in-vitro bond strengths between resin-modified glass ionomer, polyacid-modified composite resin, and giomer adhesive systems. Am J Orthod Dentofacial Orthop 2006; 129: 330. e11-330.e16.

5. Perdigão J, Dutra-Corrêa M, Saraceni SH, Ciaramicoli MT, Kiyan VH. Randomized clinical trial of two resinmodified glass ionomer materials: 1-year results. Oper Dent 2012; 37:591-601.

6. Quader SM, Alam M, Bashar A, Abdul Gafur, Al Mansur MA. Compressive Strength, Fluoride Release and Recharge of Giomer. UpDCJ 2013; 2: 28-37.

7. Yoon M, Kim JS, Yoo SH. changes of compressive strength and microhardness of composite resin, giomer and compomer after thermocycling treatment. J Korean Acad Pediatr Dent 2010; 37: 438-44.

8. Pulpodent, Activa bioactive restorative, technical product 2015.

9. Sawai MA, lanka A, Bhardwaj A, Jafri Z, Sultan N, Daing A. Tooth polishing: The current status. J Indian Soc Periodontol. 2015 Jul-Aug; 19: 375-80.

10. Patil SS, Rakhewar PS, Limaye PS, Chaudhari NP. A comparative evaluation of plaque-removing efficacy of air polishing and rubber-cup, bristle brush with paste polishing on oral hygiene status: A clinical study. J Int Soc Prev Community Dent. 2015;5:457-62.

11. Şen D, Göller G, Işsever H. The effect of two polishing pastes on the surface roughness of bis-acryl composite and methacrylate-based resins. J Prosthet Dent 2002; 88:527-32.

12. Ono M, Nikaido T, Ikeda M, Imai S, Hanada N, Tagami J, et al. Surface properties of resin composite materials relative to biofilm formation. Dent Mater J 2007; 26: 613-22.
13. Aykent F, Yondem I, Ozyesil AG, Gunal SK, Avunduk MC, Ozkan S. Effect of different finishing techniques for restorative materials on surface roughness and bacterial adhesion. J Prosthet Dent 2010; 103: 221-7.

14. Crawford RJ, Webb HK, Truong VK, Hasan J, Ivanova EP. Surface topographical factors influencing bacterial attachment. Adv Colloid Interface Sci 2012; 1: 179-82.

15. Giacomelli L, Derchi G, Frustaci A, Bruno O, Covani U, Barone A. Surface roughness of commercial composites after different polishing protocols: an analysis with atomic force microscopy. Open Dent J 2010; 4: 191-4.

16. Yap AU, Ng JJ, Yap SH, Teo CK. Surface finish of resinmodified and highly viscous glass ionomer cements produced by new one-step systems. Oper Dent 2004; 29:87-91.

17. Bala O, Arisu HD, Yikilgan I, Arslan S, Gullu A. Evaluation of surface roughness and hardness of different glass ionomer cements. Eur J Dent 2012; 6: 79-86.

18. Bayrak GD, Sandalli N, Selvi-Kuvvetli S, Topcuoglu N, Kulekci G. Effect of two different polishing systems on fluoride release, surface roughness and bacterial adhesion of newly developed restorative materials. J Esthet Restor Dent 2017; 1-11.

19. Cazzaniga G, Ottobelli M, Ionescu AC, Paolone G, Gherlone E, Ferracane JL, Brambilla E. In vitro biofilm formation on resin-based composites after different finishing and polishing procedures. J Dent 2017; 67: 43-52.

20. Jefferies SR. Abrasive Finishing and Polishing in Restorative Dentistry: A State-of-the-Art Review. Dent Clin North Am. 2007 Apr;51:379-97.

21. Özgünaltay G, Yazici AR, Görücü J. Effect of finishing and polishing procedures on the surface roughness of new toothcolored restoratives. J Oral Rehabil. 2003;30:218-24.

22. Chour RG, Moda A, Arora A, Arafath MY, Shetty VK, Rishal Y. Comparative evaluation of effect of different polishing systems on surface roughness of composite resin: An in vitro study. J Int Soc Prev Community Dent. 2016;6:166-70.

23. Bashetty K, Joshi S. The effect of one-step and multi-step polishing systems on surface texture of two different resin composites. J Conserv Dent 2010; 13:34-8.

24. Hafez R, Ahmed D, Yousry M, El-Badrawy W, El-Mowafy O. Effect of in-office bleaching on color and surface roughness of composite restoratives. Eur J Dent 2010; 4: 118-127. 
25. Kaminedi RR, Penumatsa NV, Priya T, Baroudi K. The influence of finishing/polishing time and cooling system on surface roughness and microhardness of two different types of composite resin restorations. J Int Soc Prevent Communit Dent 2014; 4: 99-104.

26. Lefever D, Perakis N, Roig M, Krejci I, Ardu S. The effect of tooth brushing on surface gloss of resin composites. Am J Dent 2012; 25: 54- 58.

27. Kirk SE, Skepper JN, Donald AM. Application of environmental scanning electron microscopy to determine biological surface structure. J Microsc. 2009;233:205-24.

28. Güler AU, Duran İ, Yücel AÇ. Özkan P. Effects of air polishing powders on the surface roughness of composite resins. J Dent Sci 2010;5:136-43.

29. Cobb CM, Daubert DM, Davis K, Deming J, Flemmig TF, Pattison A, Roulet JF, Stambaugh RV.Consensus Conference Findings on Supragingival and Subgingival Air Polishing. Compend Contin Educ Dent. 2017;38(2):e1-e4.

30. Yap AU, Wu SS, Chelvan S, Tan ES. Effect of hygiene maintenance procedures on surface roughness of composite restoratives. Oper Dent. 2005; 30: 99-104.

31. Lai YL, Lin YC, Chang CS, Lee SY. Effects of sonic and ultrasonic scaling on the surface roughness of tooth-colored restorative materials for cervical lesions. Oper Dent. 2007; 32: 273-8.

32. Graumann SJ, Sensat ML, Stoltenberg JL. Air polishing: a review of current literature. J Dent Hyg. 2013;87:173-80.

33. Neme AL, Frazier KB, Roeder LB, Debner TL. Effect of prophylactic polishing protocols on the surface roughness of esthetic restorative materials. Oper Dent. 2002; 27:50-8.
34. Johnson WW, Barnes CM, Covey DA, Walker MP, Ross JAR.The effects of a commercial aluminum air polishing powder on dental restorative materials. J Prosthodont 2004; 13: 166-72.

35. Cooley RL, Lubow RM, Patrissi GA. The effect of an airpowder abrasive instrument on composite resin. J Am Dent Assoc1986; 112:362-4.

36. Barnes CM, Covey D, Watanabe H, Simetich B, Schulte JR, Chen H. An in vitro comparison of the effects of various air polishing powders on enamel and selected esthetic restorative materials. J Clin Dent. 2014;25(4):76-87.

37. Wu SS, Yap AU, Chelvan S, Tan ES. Effect of prophylaxis regimens on surface roughness of glass ionomer cements. Oper Dent. 2005;30:180-4.

38. Yap AU, Chew CL, Teoh SH, Ong LFKL. Influence of contact stress on OCA wear of composite restoratives. Oper Dent 2001;26:134-44.

39. Reel DC, Abrams H, Gardner SL, Mitchell RJ. Effect of ahydraulic jet prophylaxis system on composites. J Prosthet Dent 1989; 61:441-5.

40. Gutmann ME, Marker VA, Gutmann JL. Restoration surface roughness after air-powder polishing. Am J Dent 1993; 6:99-102.

41. Folwaczny M, Loher C, Mehl A, Kunzelmann K.H, Hinkel R.Tooth-colored filling materials for the restoration of cervical lesions: a 24-month follow-up study. Oper Dent 2000; 25: 251-8.

42. Mourouzis P, Koulaouzidou EA, Vassiliadis L, Helvatjoglu-Antoniades M. Effects of sonic scaling on the surface roughness of restorative materials. J Oral Sci 2009; 51:607-14. 